\title{
NOTES
}

\section{A developmental examination of ratings of associative strength}

\author{
DAVID F. BJORKLUND and JOHN W. JACOBS, III. \\ Florida Atlantic University, Boca Raton, Florida
}

Ratings of associative strength between members of pairs of categorically related words were obtained for children from Grades 3, 4,6, and 8 and for college adults. Correlations of ratings were high among the five grade levels, indicating that associative relations are an early form of semantic representation that change minimally in development.

Recently, several investigators have proposed that, unlike categorical relations, associative relations are established early in children's semantic memories and change little over the course of development (e.g., Bjorklund, 1985; Bjorklund \& de Marchena, 1984; Lange, 1978; McCauley, Weil, \& Sperber, 1976). In the present study, ratings of associative strength were obtained from subjects between the ages of 8 and 27 years. These ratings were evaluated to determine the extent to which estimates of associativity change developmentally. The ratings should be useful to researchers who wish to control for associative strength among stimuli in learning and memory experiments.

\section{METHOD}

\section{Subjects}

The subjects were children from Grades $3(n=24)$, $4(n=21), 6(n=42)$, and $8(n=43)$ and college adults $(n=50)$. Mean ages were 8 years 5 months, 9 years 5 months, 11 years 4 months, 13 years 6 months, and 27 years 0 months for the third-grade through college students, respectively. The children were students at a university-based public school. The adults were undergraduate students at Florida Atlantic University.

\section{Materials and Procedures}

Items selected for use in this study consisted of five examples from each of five taxonomic categories (ANIMALS, CLOTHING, OCCUPATIONS, SEASON-

Portions of this research were based on a thesis by the second author in partial fulfillment of the Master of Arts degree at Florida Atlantic University. We wish to thank the staff and students of Henderson University School for their cooperation in conducting this study. We also wish to thank Beth Halleck for her assistance in data collection and analysis and Barbara R. Bjorklund for comments on an earlier draft of the manuscript. John W. Jacobs is currently at Florida State University. Requests for reprints should be sent to David F. Bjorklund, Department of Psychology, Florida Atlantic University, Boca Raton, FL 33431.
INGS, and WEAPONS). The criteria for item inclusion were that the words have relatively high ratings on measures of word frequency (Kučera \& Francis, 1967) and category frequency (Battig \& Montague, 1969), and that two and only two pairs within each category be judged by the authors to be high associates. The items in each category were: ANIMALS-lion, tiger; dog, cat; cow; WEAPONS-bow, arrow; knife, sword; bomb; SEASONINGS-salt, pepper; ketchup, mustard; sugar; OCCUPATIONS-fireman, policeman; doctor, nurse; teacher; CLOTHES-hat, coat; shirt, pants; socks. The 25 words were arranged in pairs so that every word in each category was paired once with every other word in that category. Pilot testing indicated no appreciable difference in ratings of associative strength as a function of the order in which the words in a pair were presented. For this reason, each pair of words was presented only once. Also, each word was paired with at least one word from another category. In all, a list of 70 word pairs was constructed, 50 being intracategory pairs and 20 being intercategory pairs.

At each grade level, the subjects were tested in groups, with the procedure lasting approximately $15 \mathrm{~min}$. Each subject was given a written list of word pairs and was instructed to rate each pair on a scale of 1 to 5 according to the perceived associative relationship between the two words, with 1 indicating little or no associative strength and 5 indicating a very strong associative relation. Level of associativity was defined during pretest instructions as "the extent to which the first word in the pair brings to mind the second word,' with several examples of strong, medium, and weak associations being given.

\section{RESULTS AND DISCUSSION}

Mean associative strength ratings were computed for each intracategory and intercategory word pair, separately at each grade level. Intercategory ratings (e.g., lion-bow; salt-teacher) were uniformly low at each grade level, and thus were not included in subsequent analyses. With the exception of the category CLOTHES, the ratings for all high-associate pairs (e.g., dog-cat; salt-pepper) were higher than the ratings for all low-associate pairs (e.g., dog-lion; salt-mustard) at each grade level (mean associative ratings, collapsed over categories: high associates = $4.08,4.11,4.38,4.30$, and 4.26 for third-grade through college students, respectively; low associates $=2.72$, $2.79,2.46,2.39$, and 2.11 for third-grade through college students, respectively). ${ }^{1}$

The 10 intracategory word pairs in each category were ranked in terms of ratings of associative strength, and Spearman rank-order correlations were computed on these ratings among the five grade levels. With the exception of the category CLOTHES, all correlations were statisti- 
cally significant $(\mathrm{p}<.01)$, with $74 \%$ being in excess of .90 and $92 \%$ being in excess of .85 . For the category CLOTHES, correlations were high among the four oldest groups of subjects (range $=.853$ to .937 ), but lower between the third-graders and the other subjects (range $=.330$ to .648$)^{2}$

These data indicate that estimates of associative strength change relatively little over the age range of subjects tested here. For four of the five categories used in this study, average correlations between the child groups and the adults were high and showed minimal variation (mean correlations between child and adult ratings for these four categories $=.91, .95, .98$, and .98 for third- through eighth-graders, respectively). The only exception was the category CLOTHES, for which ratings of the thirdgraders differed from those of the older subjects. This differs from estimates of category typicality (Bjorklund, Thompson, \& Ornstein, 1983) and category frequency (Posnansky, 1978), which undergo more substantial changes in development. This is not to say that associative relations do not develop past the early school years; with age and experience, the number of strong associative relations in semantic memory surely expands. However, the associative links acquired early in development seem to change minimally over time, with most age changes in the structure of semantic memory being attributed to the addition or reorganization of nonassociative features and relations.

\section{REFERENCES}

Batting, W., \& Montague, W. (1969). Category names for verbal items in 56 categories: A replication and extension of the Connect- icut category norms. Journal of Experimental Psychology Monographs, 80, (3, Pt. 2).

BjokrLund, D. F. (1985). The role of conceptual knowledge in the development of organization in children's memory. In C. J. Brainerd \& M. Pressley (Eds.), Basic processes in memory development: Progress in cognitive development. New York: Springer-Verlag.

BJorklund, D. F., DE MARChENA, M. R. (1984). Developmental shifts in the basis of organization in memory: The role of associative versus categorical relatedness in children's free recall. Child Development, 55, 952-962.

Bjorklund, D. F., Thompson, B. E., \& Ornstein, P. A. (1983). Developmental trends in childen's typicality judgments. Behavior Research Methods \& Instrumentation, 15, 350-356.

KuČERA, H., \& Francis, W. N. (1967). Computational analysis of present-day American English. Providence, RI: Brown University Press.

LANGE, G. W. (1978). Organization-related processes in children's recall. In P. A. Ornstein (Ed.), Memory development in children. Hillsdale, NJ: Erlbaum

McCauley, C., WeIl, C. M., \& Sperber, R. D. (1976). The development of memory structure as reflected by semantic-primary effects. Journal of Experimental Child Psychology, 22, 511-518.

Posnansxy, C. J. (1978). Category norms for verbal items in 25 categories for children in Grades 2-6. Behavior Research Methods \& Instrumentation, 10, 819-832.

\section{NOTES}

1. A table of mean associative ratings for all intracategory word pairs can be obtained by writing the authors.

2. Spearman rank-order correlation matrices by category and grade level for ratings of associative relatedness can be obtained by writing the authors.

(Revision accepted for publication November 9, 1984.)

Notice

Blank Pages

It has come to our attention that, on rare occasions, one or two pages of a few of the thousands of copies of a given issue may be blank. Any subscriber who receives such a copy should immediately notify the Publications Office for a replacement. 